\title{
Characterization of the venom allergen-like protein (vap-1) and the fatty acid and retinol binding protein ( far-1) genes in Meloidogyne hispanica
}

\author{
Aida Duarte • Rosane Curtis • Carla Maleita • \\ Igor Tiago $\cdot$ Isabel Abrantes
}

Accepted: 14 April 2014 / Published online: 6 May 2014

(C) Koninklijke Nederlandse Planteziektenkundige Vereniging 2014

\begin{abstract}
The root-knot nematode (RKN) Meloidogyne hispanica has been found in all continents associated with a wide host range, including economically, important plants and can be considered a species of emerging importance. Considerable progress has been made to identify nematode effector genes as they are important targets for the development of novel control strategies. The effector genes, venom allergen-like protein (vap-1) and fatty acid and retinol binding protein (far-1), were identified, isolated and sequenced in $M$. hispanica (Mhi-vap-1 and Mhi-far-1) using the genome information available for the RKNs $M$. incognita and M. hapla. These genes are differentially expressed during $M$. hispanica development and their amplification products were observed from cDNA of the eggs, second-stage juveniles (J2) and adult females.
\end{abstract}

\footnotetext{
A. Duarte $(\bowtie) \cdot I$. Abrantes

IMAR - CMA, Department of Life Sciences, University of Coimbra, 3004-517 Coimbra, Portugal

e-mail: aida.damaso@hotmail.com

R. Curtis

Bionemax UK Ltd, Rothamsted Centre for Research and

Enterprise, Harpenden, Hertfordshire AL5 2JQ, UK

C. Maleita

CIEPQPF, Department of Chemical Engineering, University of Coimbra, 3030-790 Coimbra, Portugal

I. Tiago

Center of Neuroscience and Cell Biology, Department of Life

Sciences, University of Coimbra, 3004-517 Coimbra,

Portugal
}

However, Mhi-vap-1 showed the highest level of expression in $\mathrm{J} 2$. In situ hybridization analysis revealed that the Mhi-vap-1 and Mhi-far-1 transcripts are accumulated within the $\mathrm{J} 2$ subventral oesophageal glands. The specific expression in the subventral oesophagel glands and presence of the secretion signal peptide for both genes suggests that these proteins are secreted by the $\mathrm{J} 2$ and may play a role in the early parasitic stage of the infection process. These genes were also isolated and sequenced in $M$. arenaria, $M$. incognita and $M$. javanica; and phylogenetic analysis revealed that the predicted protein sequences belonging to $M$. hispanica and several other species of plant-parasitic nematodes have a high degree of conservation.

Keywords Nematode effectors · Root-knot nematodes · Secretions · Subventral oesophageal glands

\section{Introduction}

The sedentary endoparasite root-knot nematode (RKN) Meloidogyne hispanica Hirschmann (1996), detected for the first time in Seville, Spain, from the peach rootstock, Prunus persica silvestris Batsch, has a worldwide distribution, being found in all continents (Europe, Africa, Asia, Australia and North, Central and South America) associated with a wide range of host plants (Hirschmann 1996; Maleita et al. 2012a). Recent studies showed that M. hispanica can spread in Europe and move northwards; can overcome the tomato $M i-1.2$ gene and can 
attack economically important plant species and cultivars, including commercial tomato crops. These are characteristics of a polyphagous species of emerging importance, which is difficult to control with crop rotation and with the use of resistant cultivars (Maleita et al. 2011, 2012a, b, c).

Like other plant-parasitic nematodes, RKNs are known to secrete effector proteins into the host tissues which can alter plant physiology and assist the infection process (Rosso and Grenier 2011). These molecules are secreted from the nematode oesophageal gland cells, as well as from amphids and nematode surface cuticle (Davis et al. 2008; Davis and Curtis 2011; Rosso et al. 2012). A number of candidate effector genes, from both cyst nematodes and RKNs have been identified, using cDNA libraries from RNA extracted specifically from the oesophageal gland cells of these nematodes (Wang et al. 2001; Gao et al. 2003; Huang et al. 2003; Hussey et al. 2011). So far, the functions for several potential effector proteins have been predicted and showed that various cellular processes can be targeted by the nematode for successful manipulation of the host response. These include the cell wall structure, manipulation of cell fate, protein synthesis and alteration of signaling pathways. Functional tests, using RNAi, have supported the putative role of some of these nematode effectors in pathogenesis (Bellafiore et al. 2008; Roze et al. 2008; Bellafiore and Briggs 2010).

The venom allergen-like proteins (VAPs) are homologues of the plant and animal cystein-rich secretory proteins (CRISPs). Although, the VAPs are part of a family of effectors considered to be conserved in all parasitic nematodes of plants and animals, its function is still unknown (Haegeman et al. 2012). They have been identified and characterized from the RKNs M. incognita, M. hapla and M. chitwoodi, the cyst nematodes Heterodera glycines, H. schachtii and Globodera pallida, the root-lesion nematode Pratylenchus coffeae and the pinewood nematode Bursaphelenchus xylophilus (Ding et al. 2000; Gao et al. 2001; Vanholme et al. 2006; Wang et al. 2007; Opperman et al. 2008; Roze et al. 2008; Jones et al. 2009; Kang et al. 2010, 2012; Haegeman et al. 2011, 2012). Various allergen proteins were described as being highly transcribed during plant nematode parasitism (Ding et al. 2000; Gao et al. 2001; Wang et al. 2007). Some are proposed to be involved in the defence response mediated by extracellular innate immune receptors and host invasion (Hawdon et al. 1999; Murray et al. 2001). The vap-1 gene is recognized as being potentially associated with the $M$. incognita infection process, with the induction of a host immune response and resistance since it triggers a Cf-2/Rcr3pim dependent programmed cell death in tomato plants (Gao et al. 2001; Haegeman et al. 2009; Chen et al. 2010; LozanoTorres et al. 2012).

The protein FAR-1 is a member of the nematode specific fatty-acid and retinol binding (FAR) family of proteins and was detected for the first time in G. pallida. This protein is present in the surface coat of potato cyst nematode species and binds fatty acids, including linoleic acids that are precursor of plant defence compounds (Prior et al. 2001). These fatty acids are metabolized by lipoxygenase as part of the signalling pathway leading to the production of jasmonic acid and FAR-1 inhibited this biochemical process in vitro thus may have a role in the suppression of jasmonate synthesis and of the downstream signalling pathways, reducing host defences (Curtis 2007; Haegeman et al. 2012). A study with $M$. javanica suggests that the MJ-FAR-1 protein has an important role in the infection process. FAR-1 induces susceptibility to RKN through the manipulation of jasmonate-dependent defence response (Iberkleid et al. 2013). FAR-1 has also been identified in H. schachtii, M. chitwoodi, M. hapla, M. incognita, P. coffeae and Radopholus similis (Vanholme et al. 2006; Bellafiore et al. 2008; Jacob et al. 2008; Opperman et al. 2008; Roze et al. 2008; Haegeman et al. 2009, 2011).

The main goals of this research were to isolate, to characterize the expression and to localize the vap-1 and far-1 genes in $M$. hispanica, which may be good targets for the development of novel control strategies for this species, and also to investigate the phylogenetic relationship of M. hispanica with other Meloidogyne species.

\section{Material and methods}

Nematode isolate

The M. hispanica isolate used in this study was originally obtained from infected fig tree (Ficus carica L.) roots collected in Odeceixe, Faro, Portugal; the $M$. incognita isolate was provided by Rothamsted Research, UK; and the Portuguese isolates of $M$. arenaria and $M$. javanica were originally obtained from Oxalis corniculata L. and Solanum tuberosum L. 
roots, respectively. All the isolates were maintained on tomato, S. lycopersicum L., cv. Tiny Tim, in pots containing sterilized sandy loam soil and sand (1:1), in a growth chamber, at $25 \pm 2{ }^{\circ} \mathrm{C}$, with approximately $75 \%$ relative humidity. Two months after the inoculation with 10 egg masses (EM), the eggs were extracted using $0.52 \%$ sodium hypochlorite $(\mathrm{NaOCl})$ solution (Hussey and Barker 1973), the freshly hatched J2 were obtained from the EM placed on a $25 \mu \mathrm{m}$ mesh sieve, and the females extracted from galled roots. The species identification was confirmed by esterase phenotype analysis (Pais et al. 1986; Abrantes et al. 2008).

Bioinformatics and sequence analyses

Homolog proteins VAP-1 and FAR-1 sequences were searched in the National Center for Biotecnology information (Genbank accessions N ${ }^{\circ}$. ABL61274.1 for VAP1 in $M$. arenaria and $\mathrm{N}^{\circ}$. CAA70477.2 for FAR-1 in G. pallida). Gene models were attributed to expressed sequence tag (EST) contigs using tblastn searches against the predicted proteins from the genome of M. incognita (http://www.inra.fr/meloidogyne_incognita). The same criteria were used to attribute gene models from the M. hapla genome (http://www.pngg.org/cbnp/ index.php). Putative orthologs were searched by reciprocal best-hit comparison, using gene models from the genome of M. incognita (Minc17158) and M. hapla (Mh10g200708_contig2874) for vap-1 and from the genome of M. incognita (Minc08986) and M. hapla (Mh10g200708_contig113) for far-1.

Alignments were analysed in the program Multiple Sequence Alignment by Florence Corpet (MultAlin Hosted by the Plateforme Bioinformatique Genotoul). After the alignment, the conserved regions of the DNA sequences of vap-1 and far- 1 in the two species of RKN, M. incognita and M. hapla, were used to design primers using the program Vector NTI (Invitrogen, UK). For vap-1 gene, the primers were MIHA-VAP-1f/MIHAVAP-1r and for far-1 MIHA-FAR-1f/MIHA-FAR-1r (Table 1).

\section{DNA extraction}

Genomic DNA was extracted from $M$. hispanica, $M$. arenaria, $M$. incognita and $M$. javanica J2, using an adaptation of the protocol described by Orui (1999). Nematodes were homogenized in nitrogen liquid with $400 \mu \mathrm{l}$ of extraction buffer $(200 \mathrm{mM}$ Tris- $\mathrm{HCl} \mathrm{pH} 8$;
Table 1 Primers used in this study

\begin{tabular}{ll}
\hline Primer name & Primer sequence $\left(5^{\prime} \rightarrow 3^{\prime}\right)$ \\
\hline MIHA-VAP-1f & TGGGCTGATAAATGCACTTA \\
MIHA-VAP-1r & GTGTCCAATGTCCAATACCT \\
MIHA-FAR-1f & GGCTAGGGTTAATAAGATTTG \\
MIHA-FAR-1r & CCTTCTGGTTTCAACAAGCT \\
MHI-VAP-1f & TTATGGAGAGATTTCTATGC \\
MHI-VAP-1r & GTGTCCAATGTCCAATACCT \\
MHI-FAR-1f & GATTTGGTCCGCCTGAGGTT \\
MHI-FAR-1r & CGGTAATCTTGGGGAAGTTG \\
$\beta$-actinf & GATGGCTACAGCTGCTTCGT \\
$\beta$-actinr & GGACAGTGTTGGCGTAAAGG \\
M13f & CGCCAGGGTTTTCCCAGTCACGAC \\
M13r & TCACACAGGAAACAGCTATGAC \\
\hline
\end{tabular}

$250 \mathrm{mM} \mathrm{NaCl}$ and $25 \mathrm{mM}$ EDTA) and centrifuged at $20,000 \times \mathrm{g}$ for $5 \mathrm{~min}$. The supernatant was transferred to a new tube and equal volume of isopropanol was added. After swirling the tube, the mixture was incubated at room temperature for $30 \mathrm{~min}$ and centrifuged at $20,000 \times \mathrm{g}$ for $15 \mathrm{~min}$. The supernatant was removed and the pellet washed with $500 \mu \mathrm{L}$ of $70 \%$ ethanol. After centrifugation for $5 \mathrm{~min}$ at $20,000 \times \mathrm{g}$, the supernatant was removed and the pellet dried. The DNA was then resuspended in $30 \mu \mathrm{l}$ of Tris-EDTA (10 mM Tris$\mathrm{HCl} \mathrm{pH} 8$ and $1 \mathrm{mM}$ EDTA) and the concentration determined in a Nanodrop ND-1000 Spectrophotometer (Labtech International, UK).

Amplification of vap-1 and far-1 genes

PCR amplifications were performed in a mixture containing $25 \mathrm{ng}$ of $M$. hispanica, $M$. arenaria, $M$. incognita, or M. javanica DNA as template and five units of Taq DNA polymerase (Promega, UK), in 1x Go Taq Reaction Buffer, $1.5 \mathrm{mM} \mathrm{MgCl}_{2}, 10 \mathrm{mM}$ dNTP's, and $10 \mu \mathrm{M}$ of each primer, vap-1 primers were MIHA-VAP1f/MIHA-VAP-1r and MIHA-FAR-1f/MIHA-FAR-1r for far-1 (Table 1). Amplifications were carried out using the following conditions: $3 \mathrm{~min}$ at $95^{\circ} \mathrm{C}, 40$ cycles at $95^{\circ} \mathrm{C}$ for $30 \mathrm{~s}, 40^{\circ} \mathrm{C}$ for $30 \mathrm{~s}$ and $72^{\circ} \mathrm{C}$ for $2 \mathrm{~min}$ and a final extension at $72{ }^{\circ} \mathrm{C}$ for $5 \mathrm{~min}$. The PCR reaction was analysed on a $1.0 \%$ agarose gel in $1 \mathrm{x}$ TAE buffer stained with GreenSafe (NZYTech, Portugal). The amplified products were purified with the QIAquick Gel Extraction Kit (QIAGEN, UK) and sequenced by 
standard procedures at Eurofins MWG Operon (Ebersberg, Germany). The sequences designated as Ma-vap-1, Mhi-vap-1, Mi-vap-1, Mj-vap-1, Ma-far-1, Mhi- far-1, Mi-far-1 and Mj-far-1 were deposited in GenBank as KF030969, KF030970, KF030971, KF030972, KF030973, KF030974, KF030975 and KF030976, respectively. Meloidogyne hispanica specific primers (MHI-VAP-1f/MHI-VAP-1r and MHI-FAR1f/MHI-FAR-1r) were designed from conserved sequences between this species and $M$. incognita, located in the 3'UTR region, as described before (Table 1).

RNA extraction and developmental expression analysis

Total RNA was extracted from $M$. hispanica eggs, J2 and adult females. The specimens were placed in liquid nitrogen and homogenized, separately, using the sample preparation system MP Fast Prep-24, speed at $4.0 \mathrm{~m} / \mathrm{s}$ (MP Biomedicals, California, USA). Afterwards, the RNA was isolated using the RNeasy Mini Kit including RNase-Free DNase Set (QIAGEN, UK). The concentration and purity of the RNA was determined in a Nanodrop ND-1000 Spectrophotometer. Total RNA (180 ng) of each developmental stage was reverse transcribed into cDNA using the SuperScript II Reverse Transcriptase (Invitrogen, UK), according to the manufacturer's instructions, and the concentration determined. After the reverse transcriptase reaction, a standard PCR was performed with the M. hispanica vap-1 and far-1 specific primers (Table 1). Actin genes were amplified from each sample as positive control (Table 1). The PCR mixture, containing $25 \mathrm{ng}$ of synthesized cDNA template and five units of Taq DNA polymerase (Promega, UK), in 1x Go Taq Reaction Buffer, $1.5 \mathrm{mM} \mathrm{MgCl} 2,10 \mathrm{mM}$ dNTP's and $10 \mu \mathrm{M}$ of each primer, was first heated for $3 \mathrm{~min}$ at $95^{\circ} \mathrm{C}$, and then submitted to 39 temperature cycles $\left(95{ }^{\circ} \mathrm{C}\right.$ for $30 \mathrm{~s}$, $40{ }^{\circ} \mathrm{C}$ for $30 \mathrm{~s}$, and $72{ }^{\circ} \mathrm{C}$ for $1.5 \mathrm{~min}$ ) with a final extension at $72{ }^{\circ} \mathrm{C}$ for $5 \mathrm{~min}$.

Genomic clone

Amplified M. hispanica cDNA fragments were purified, as described above, cloned into pGEM-T Easy vector (Promega, UK), and transformed into Escherichia coli DH5-alfa by electroporation, in a Micro-Pulser (BioRad, Hercules, California, US). One positive clone of each Mhi-vap-1 and Mhi-far-1genes was selected and amplified with the primers M13f/M13r (Table 1).
mRNA in situ hybridization

For in situ hybridization, the DNA fragment used as probe was amplified from the cloned cDNA of $M$. hispanica $\mathrm{J} 2$ with the designed specific primers MHI-VAP-1f/MHI-VAP-1r and MHI-FAR-1f/MHIFAR-1r. $10 \mathrm{ng}$ of each purified PCR product (QIAquick PCR purification Kit, QIAGEN, UK) was the template in an asymmetric PCR to synthesize digoxigenin (DIG)-labelled sense and antisense singlestranded cDNA probes with PCR DIG Probe Synthesis kit (Roche Applied Science, Indianapolis, USA) (Lee et al. 2006). In situ hybridization was performed with M. hispanica J2 as described by De Boer et al. (1998).

Phylogenetic analysis

The vap-1 and far- 1 sequences of $M$. hapla were obtained from M. hapla genome website (http://www.pngg.org/ cbnp/index.php?option $=$ com_wrapper\&Itemid $=45$ ) and far-1 sequence of G. pallida was obtained from GenBank nucleotide database. The vap-1 and far-1 sequences of the $M$. arenaria, $M$. hispanica, $M$. incognita and $M$. javanica isolates were aligned with the ones from M. hapla and G. pallida sequences, and truncated to obtain a common start and end point. The alignment allowed the identification of the additional coding sequence of each sequence and the removal of introns. The amino acid sequences were deduced, from the 206 bp and 396 bp DNA sequences for the partial vap-1 and far-1 sequences, respectively. Protein phylogenetic trees were constructed using the Neighbor-Joining (Saitou and Nei 1987) and Maximum-Likelihood (Jones et al. 1992) algorithms, and topology of the trees were generated from evolutionary distances computed using the Poisson correction method (Zuckerkandl and Pauling 1965), included in MEGA5 (Tamura et al. 2011). The topology of the trees generated was evaluated by performing bootstrap analysis (Felsenstein 1985) of 500 resamplings of the data set. All positions with less than $75 \%$ site coverage were eliminated. The protein alignment was used to determine the nucleotide position in the DNA sequences alignment, that was further used to perform DNA sequences phylogenetic analyses as described above, but the evolutionary distances were computed using the Jukes-Cantor correction method included in MEGA5 (Jukes and Cantor 1969; Tamura et al. 2011). 


\section{Results}

Bioinformatics analyses and amplification of vap-1 and far- 1 genes

The protein homology search of VAP-1 (accession $\mathrm{N}^{\circ}$. ABO38109) and FAR-1 (accession $\mathrm{N}^{\circ}$. CAA70477.2) in the databank, using tblastn, revealed $76 \%$ (Minc17158) and $53 \%$ (Minc08986) protein identity, respectively to $M$. incognita and $85 \%$ (MhA1_Contig2874) and $88 \%$ (MhA1_Contig113) to M. hapla. Based in analysis of EST from $M$. incognita and M. hapla, a pair of primers was designed for each region which permitted the successful amplification of a fragment of approximately $280 \mathrm{bp}$ for vap- 1 and $700 \mathrm{bp}$ for far-1, from all Meloidogyne species used in this study (data is only shown for M. hispanica J2, Fig. 1).

Transcription analysis of Mhi-vap-1 and Mhi-far-1 genes

Reverse transcription polymerase chain reaction was used to evaluate the expression of the genes Mhi-vap-1 and Mhi-far-1 in three M. hispanica developmental stages (eggs, J2 and females), and specific bands of approximately $200 \mathrm{bp}$ and $400 \mathrm{bp}$ were, respectively amplified in these developmental stages (Fig. 2). The cDNA fragments were amplified in all of the nematode samples. However, the expression of Mhi-vap-1 was

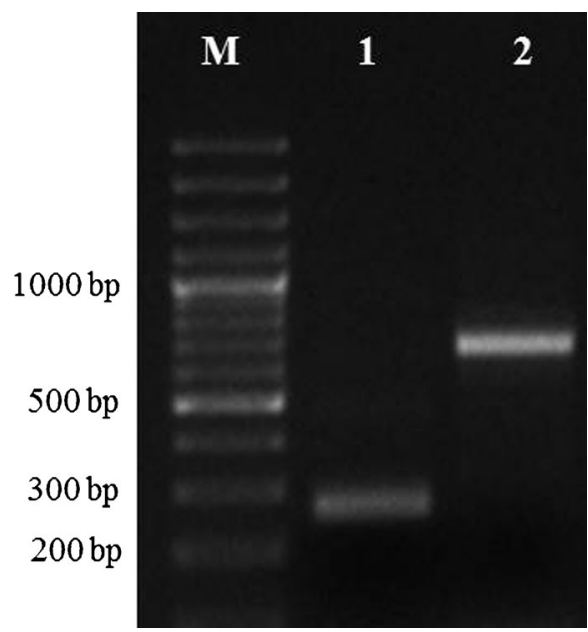

Fig. 1 DNA amplification products of Meloidogyne hispanica second-stage juveniles using MIHA-VAP-1f/MHIHA-VAP-1r (1) and MIHA-FAR-1f/MIHA-FAR-1r (2) primers. Lane M, DNA marker (GeneRuler $1 \mathrm{~kb}$ Plus DNA ladder, Fermentas)

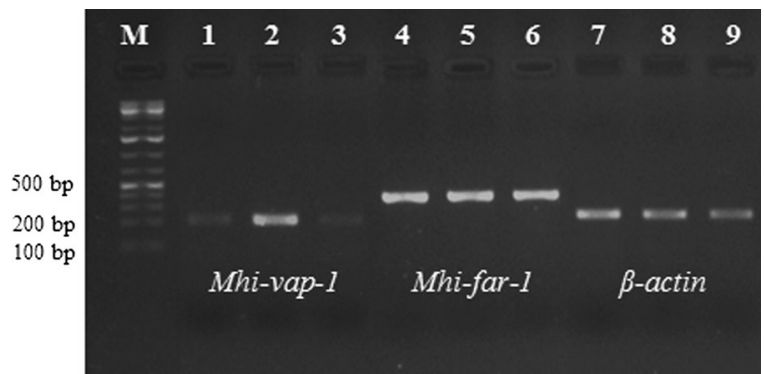

Fig. 2 Expression of the Mhi-vap-1 and Mhi-far-1 genes detected by reverse transcriptase mediated PCR amplification of cDNAs from Meloidogyne hispanica eggs, second-stage juveniles (J2) and females. Lanes 1, 4 and 7 cDNA templates from eggs; lanes 2, 5 and $8 \mathrm{~J} 2$ cDNA; lanes 3, 6 and 9 females cDNA; lane M, DNA marker (GeneRuler $1 \mathrm{~kb}$ DNA ladder, Fermentas). As a positive control, cDNA templates were amplified with the primers of $\beta$ actin gene

higher in $\mathrm{J} 2$ when compared with those obtained in eggs and females. For Mhi-far-1, the expression was equally higher in all the developmental stages (Fig. 2).

In order to localize the expression of the genes Mhivap-1 and Mhi-far- 1 in nematodes, in situ hybridization experiments were performed. Sense and antisense cDNA probes were used against $M$. hispanica J2. The genes specific antisense cDNA probe specifically hybridized with mRNA accumulated within the subventral oesophageal gland cells of J2 (Fig. 3b and d). No hybridization signal was detected in the nematode when using control sense probes (Fig. 3a and c).

\section{Phylogenetic analyses}

Using the primers designed in this work (MIHA-VAP$1 \mathrm{f} / \mathrm{r}$ and MIHA- FAR-1f/r), vap- 1 and far- 1 were identified and successfully amplified in $M$. hispanica and in three additional Meloidogyne species. The sequences obtained were used for further phylogenetic analyses of the predicted amino acid and partial gene sequences (Figs. 5 and 6). Analyzing the multiple alignments obtained to VAP-1 and FAR-1, the MHI-VAP-1 sequence differed by two amino acid positions from $M$. incognita and 11 from M. hapla while MHI-FAR-1 differed from M. hapla six positions (Fig. 4). Globodera pallida, GPFAR-1, showed 43 amino acid differences in alignment with the other Meloidogyne species (Fig. 4b). The MHIVAP-1 amino acid sequences displayed sequence identities ranging from 77.2 (M. hapla) to $100 \%$ (M. arenaria and $M$. javanica) when compared with the other species and the MHI-FAR-1 from 63.9 


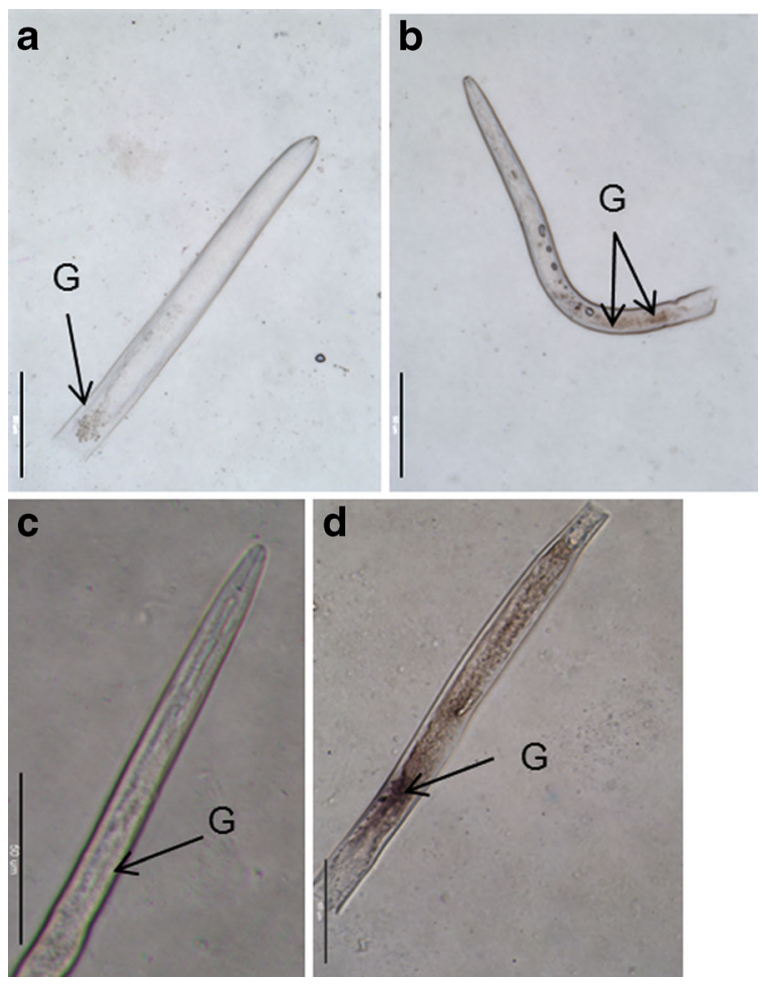

Fig. 3 Meloidogyne hispanica second-stage juveniles (J2) sections hybridized with digoxigenin-labeled sense and antisense cDNA probes derived from the Mhi-vap-1 (a and b) and Mhi- far-1 (c and d) genes. $\mathbf{a}$ and $\mathbf{c}$ - Alkaline phosphatase staining is absent in J2 that have been incubated with the sense probe. $\mathbf{b}$ and $\mathbf{d}$ - Alkaline phosphatase staining shows specific binding of the antisense probe to the cytoplasm of the subventral oesophageal gland cells $(G)$. Scale bars $=50 \mu \mathrm{m}$

(G. pallida) to $100 \%$ (M. arenaria, M. incognita and $M$. javanica) (Tables 2 and 3). The phylogenetic analyses revealed that VAP-1 shared high protein homology and phylogenetic relations with $M$. hispanica, M. arenaria, and M. javanica (Fig. 5a), whereas FAR1 was closely related to the four RKN species, $M$. hispanica, $M$. arenaria, $M$. incognita and M. javanica (Fig. 5b). In both proteins, M. hapla was the most divergent RKN species (Fig. 5).

The topology of the VAP-1 tree was identical to the one obtained from DNA sequences (Figs. 5a and 6a). The topology of the FAR-1 protein and DNA trees exhibited some differences, specifically on the cluster formed by $M$. hispanica, M. arenaria, M. incognita and M. javanica (Figs. 5b and 6b). These results are congruent with the differences observed between the identity values determined for the protein and DNA alignments (Tables 3 and 5). Mhi-vap-1 sequence exhibited sequence similarity values ranging from $83.7 \%$
(M. hapla) to $100 \%$ (M. arenaria and M. javanica) (Table 4) and formed a closed cluster with $M$. arenaria and M.javanica (Fig. 6a). Mhi-far-1 displayed sequence similarity values of $55.5 \%$ towards G. pallida and from 87.7 to $100 \%$ towards Meloidogyne spp. (Table 5) and formed a well-supported clade with $M$. incognita with $100 \%$ bootstrap (Fig. 6b). Meloidogyne hapla was the most divergent Meloidogyne spp. (Fig. 6a and b).

In fact, the protein alignment identity values decreased slightly when compared to the values obtained from DNA sequences alignment (Tables 3 and 5), most probably related with the presence of synonymous mutation, thus explaining the difference of the phylogenetic results.

\section{Discussion}

The effector genes vap-1 and far-1 (encoding proteins VAP-1 and FAR-1, respectively) have been identified for the first time in $M$. hispanica and the partial sequences of these genes were successfully amplified. The phylogenetic analyses, conducted on VAP-1 and FAR-1 and on partial genes sequences, determined that $M$. hispanica was most closely related with $M$. arenaria, M. incognita and M. javanica, and M. hapla was the most divergent of the Meloidogyne species. The presence of synonymous mutation was also observed indicating a conservation of the protein sequences within the Meloidogyne species, most probably due to its functional specificity.

Two types of VAPs have been identified in nematodes: a short single domain type, of approximately 220 amino acids, and a longer double domain type of approximately 425 amino acids (Bin et al. 1999; Hawdon et al. 1999; Gao et al. 2001). Meloidogyne hispanica MHI-VAP-1 is representative of the single domain venom allergen-like protein, the most common type found in nematodes (Gao et al. 2001).

Multiple sequence alignment showed that MHAVAP-1 contains the most variant amino acids residues compared with $M$. hispanica, $M$. arenaria and M. javanica. MHI-VAP-1 partial predicted amino acid sequence has $100 \%$ homology with MA-VAP-1 and MJ-VAP-1, indicating a strong conservation of these proteins.

Previous phylogenetic studies demonstrated that FAR homologues from the animal parasitic nematodes Onchocerca, Brugia, Wuchereria, Loa, 


\begin{tabular}{|c|c|c|c|c|}
\hline a & 10 & 30 & 50 & \\
\hline MHI-VAP-1 & $\begin{array}{l}\ldots 1 \ldots 1 \\
\text { TYSHSNPYGN YGENFYAYAR }\end{array}$ & MDNDSAAIEY VVKGWWSELI & $\begin{array}{l}\ldots|\ldots| \\
\text { YRGALGPYPG }\end{array}$ & QDCV 54 \\
\hline MA-VAP-1 & TYSHSNPYGN YGENFYAYAR & MDNDSAAIEY VVKGWWSELI & YRGALGPYPG & QDCV 54 \\
\hline MHA-VAP-1 & TYSHSDPAGS YGENFYAYSR & FDNDSAAIEY VVKGWWIAELT & VRGAVAPEPG & QDCV 54 \\
\hline MI-VAP-1 & TYSHSNPYGN YGENFYAYAR & MDNDAAAIEY VVKGWWSELE & YRGALGPYPG & QDCV 54 \\
\hline MJ-VAP-1 & $\begin{array}{rr}\text { TYSHSNPYGN } & \text { YGENFYAYAR } \\
* * * & *\end{array}$ & $\begin{array}{l}\text { MDNDSAAIEY VVKGWWSELI } \\
* * * *\end{array}$ & $\begin{array}{l}\text { YRGALGPYPG } \\
* \quad * * *\end{array}$ & QDCV 54 \\
\hline
\end{tabular}

b

MHI-FAR-1

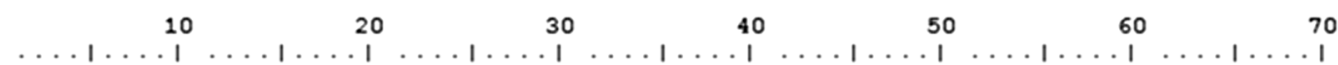

DLVPPEVTTF YNELTEDDKK ILKEVAEKHS EYATDEDALN ALKERSEKLY TRANELRNLV KDRISKLNPE MA-FAR-1 DLVPPEVTTF YNELTEDDKK ILKEVAEKHS EYATDEDALN ALKEKSEKLY TRANELRNLV KDRISKLNPE MHA-FAR-1 DLVPPEVTTF YNELTEDDKL ILKEIAKKHD EYATDEDALN ALKEKSEKLY TKANELRNLV KDRISKLNPE MI-FAR-1 DLVPPEVTTF YNELTEDDKK ILKEVAEKHS EYATDEDALN ALKEKSEKLY TKANELRNLV KDRISKLNPE MJ-FAR-1 DLVPPEVTTF YNELTEDDKK ILKEVAEKHS EYATDEDALN ALKEKSEKLY TKANELRNLV KDRISKLNPE

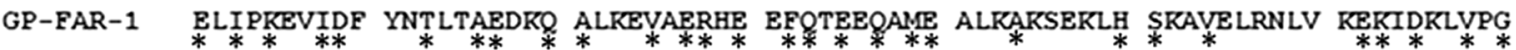

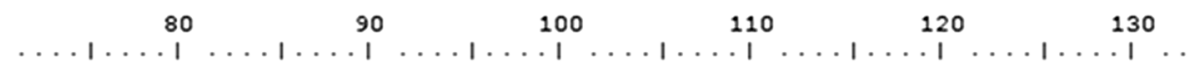

MHI-FAR-1 AKTFVDTIIE KLRALRPKKD EKPNLTELRK EANEIVEKFK ALSBEAKESL KTNFPKITGV IQ 132

MA-FAR-1 AKTFVDTIIE KLKALRPKKD EKPNLTELRK EANEIVEKFK ALSEEAKESL KTNFPKITGV IQ 132

MHA-FAR-1 AKTFVDTIIE KIKALRPKKD EKPNLTELRK EANEIIEKFK ALSEEAKESL KTNFPKITGV IQ 132

MI-FAR-1 AKTFVDTIIE KLKALRPKKD EKPNLTELRK EANEIVEKFK ALSEEAKESL KTNFPKITGV IQ 132

MJ-FAR-1 AKTFVDTIIE KLKALRPKIRD EKPNLTELRK EANEIVEKFK ALSEEAKESL KTNFPKITGV IQ 132

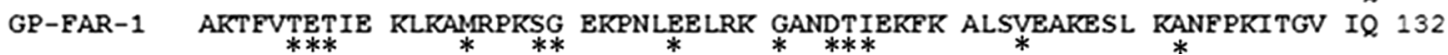

Fig. 4 Multiple sequence alignment of Meloidogyne hispanica venom allergen-like protein, MHI-VAP-1 (KF030969) (a), and fatty acid and retinol binding protein, MHI-FAR-1 (KF030974) (b), amino acid sequences with homologues from other phytoparasitic nematodes. MA-VAP-1 (KF030971) and MAFAR-1 (KF030973) from M. arenaria; MHA-VAP-1

Acanthocheilonema, Ascaris suum, Toxocara canis, and Litomosoides, and the plant-parasitic nematodes G. pallida, G. rostochiensis, $M$. javanica, M. arenaria, H. schachtii, P. vulnus and R. similis, and the free-living nematode Caenorhabditis elegans were closely related and they all share conserved amino acid sequences in its primary and secondary structures (Prior et al. 2001; Garofalo et al. 2002; Iberkleid et al. 2013). Mj-FAR-1 grouped closely with FARs belonging to other parasitic nematodes (animal, sedentary, and migratory plantparasitic nematodes). However, FAR proteins clearly distinguished and grouped different nematode species according to their trophic group and nematode parasitism strategy. The highest predicted amino acid identity of Mj-FAR-1 was found amongst $M$. incognita, $M$. arenaria and M. hapla and the lowest observed between M. javanica and M. chitwoodi (Iberkleid et al. 2013). Although, there is a strong conservation for this group of proteins, M. hapla in this study showed to be the most divergent when compared with $M$. hispanica, which might account for a particular mode of parasitism adaptation and/or reproduction. Meloidogyne hapla
( MhA 1 contig2874) and MHA-FAR-1 (Mh10g200708_contig113) from M. hapla; MI-VAP-1 (KF030970) and MI-FAR-1 (KF030975) from M. incognita; MJVAP-1 (KF030972) and MJ-FAR-1(KF030976) from M. javanica and GP-FAR-1 (CAA70477.2) from Globodera pallida. Differences between amino acids are indicated by asterisks

reproduce by facultative meiotic or mitotic parthenogenesis while $M$. hispanica, $M$. arenaria, $M$. incognita and $M$. javanica reproduce by obligatory mitotic parthenogenesis (Chitwoodi and Perry 2009).

The high degree of conservation in the lipid-binding characteristics of FAR proteins and their presence at the host parasite interface, across multiple families of para-

Table 2 Pairwise sequence identities among Meloidogyne hispanica (MHI-VAP-1, KF030969), M. arenaria (MA-VAP-1, KF030971), M. hapla (MHA-VAP-1, MhA1_contig2874), M. incognita (MI-VAP-1, KF030970) and M. javanica (MJVAP-1, KF030972) sequences of VAP-1 protein using the Poisson correction method included in MEGA5

MHI-VAP-1 MI-VAP-1 MA-VAP-1 MJ-VAP-1

\begin{tabular}{lllll}
\hline MI-VAP-1 & 96.2 & & & \\
MA-VAP-1 & 100 & 96.2 & & \\
MJ-VAP-1 & 100 & 96.2 & 100 & \\
MHA- & 77.2 & 74.9 & 77.2 & 77.2 \\
VAP-1 & & & & \\
\hline
\end{tabular}


Table 3 Pairwise sequence identities among Meloidogyne hispanica (MHI-FAR-1, KF030974), M. arenaria (MA-FAR-1, KF030973), M. hapla (MHA-FAR-1, Mh10g200708_contig113), M. incognita (MI-FAR-1, KF030975), M. javanica (MJ-FAR-1, KF030976) and Globodera pallida (GP-FAR-1, CAA70477.2) sequences of FAR-1 protein using the Poisson correction method included in MEGA5

\begin{tabular}{llllll}
\hline & $\begin{array}{l}\text { MHI- } \\
\text { FAR-1 }\end{array}$ & $\begin{array}{l}\text { MI- } \\
\text { FAR-1 }\end{array}$ & $\begin{array}{l}\text { MA- } \\
\text { FAR-1 }\end{array}$ & $\begin{array}{l}\text { MJ- } \\
\text { FAR-1 }\end{array}$ & $\begin{array}{l}\text { MHA- } \\
\text { FAR-1 }\end{array}$ \\
\hline MI-FAR-1 & 100 & & & & \\
MA-FAR-1 & 100 & 100 & & & \\
MJ-FAR-1 & 100 & 100 & 100 & & \\
MHA-FAR-1 & 95.3 & 95.3 & 95.3 & 95.3 & \\
GP-FAR-1 & 63.9 & 63.9 & 63.9 & 63.9 & 61.7 \\
\hline
\end{tabular}

sitic nematodes, support the hypothesis that this nematode restricted family of proteins play a crucial role in the life cycle, and in the parasitism of their host (Bath et al. 2009). Only six differences were observed in the predicted amino acid sequences between MHA-FAR-1 and MHI-FAR-1, MA-FAR-1, MI-FAR-1 and MJ-FAR-1.

The cDNA transcription analysis demonstrated that Mhi-vap-1 and Mhi-far-1 genes were transcribed in eggs, J2 and females. Moreover, a high expression of MHI-VAP-1 was evidenced in M. hispanica J2 and a very low level of expression was detected in eggs. In contrast, almost equal expression of MHI-FAR-1 was detected in eggs, J2 and females, which suggest a potential role during the different developmental stages.

The localization of the Mhi-vap-1 and Mhi-far-1 transcripts in $\mathrm{J} 2$, by in situ hybridization, revealed that there is a specific binding of the antisense probe to the subventral oesophageal glands. These results suggest that, in M. hispanica VAP-1 and FAR-1 might be natural components of the nematode secretions which are released through the stylet by the $\mathrm{J} 2$.

Remarkable similarities of VAP proteins to allergens from hymenopteran insect venoms were found and the in situ hybridization showed that homologues of this gene are present in the gland cells of $H$. glycines and Ditylenchus destructor (Gao et al. 2001; Peng et al. 2013). Furthermore, the venom allergen AG5-like protein and the Mi-vap-2 gene were expressed exclusively in the oesophageal glands of pre-parasitic and parasitic J2 of M. incognita (Ding et al. 2000; Wang et al. 2007) while the Mhi-vap-1 was detected in oesophageal glands of pre-parasitic $\mathrm{J} 2$ being weakly transcribed in eggs and females. Animal parasitic allergen genes have been associated with the induction of a host immune response (Chen et al. 2010) and the effector Gr-VAP-1, localized in the subventral oesophageal glands of $G$. rostochiensis pre-parasitic $\mathrm{J} 2$, has also been implicated in resistance (Lozano-Torres et al. 2012).
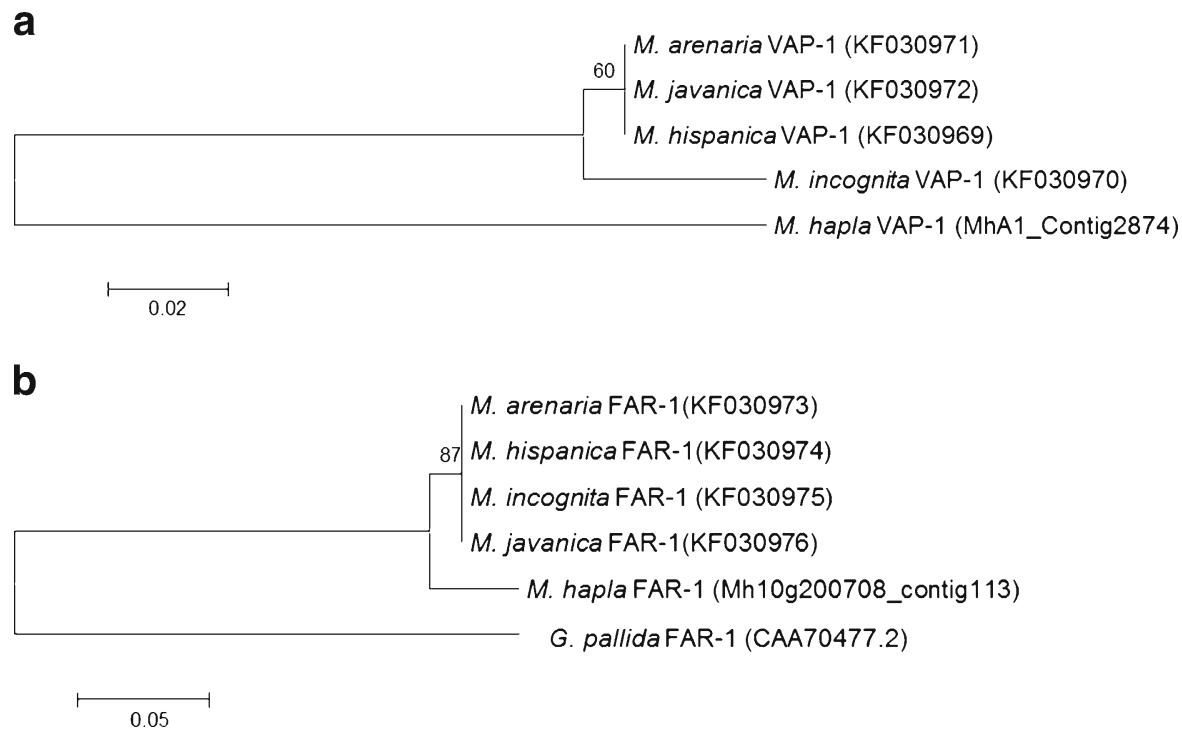

Fig. 5 Phylogenetic trees constructed on the basis of the predicted venom allergen like protein (VAP-1) sequences from Meloidogyne hispanica, M. arenaria, M. hapla, M. incognita and $M$. javanica (a) and fatty acid and retinol binding protein (FAR-1) sequences from M. hispanica, M. arenaria, M. hapla, M. incognita, M. javanica and Globodera pallida (b). The percentage of replicate trees in which the associated taxa clustered together in the bootstrap test (500 replicates) is shown next to the branches 
a

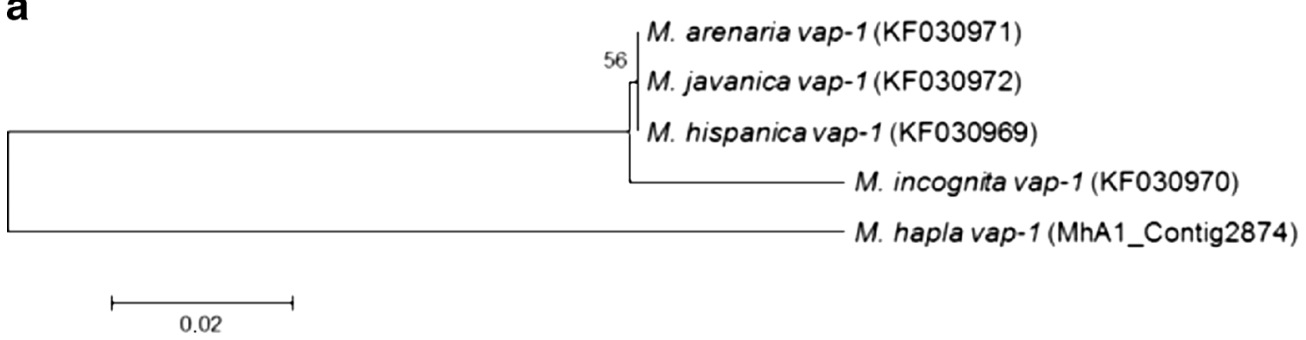

b

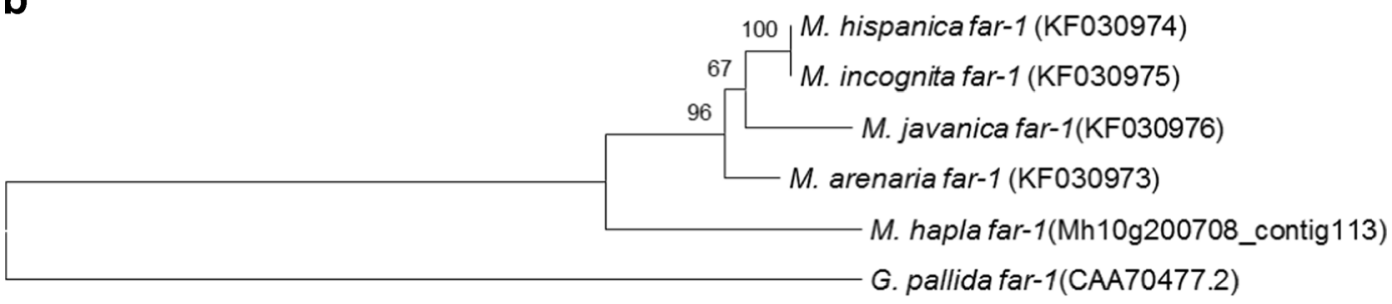

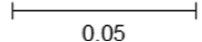

Fig. 6 Phylogenetic analysis of the venom allergen like protein (vap-1; A) and fatty acid and retinol binding protein (far-1; B) gene sequences. Meloidogyne hapla and Globodera pallida were

Using RT-PCR, this study shows that equal expression of MHI-FAR-1 was detected in eggs, J2 and females however, quantitative real time PCR indicates that for M. javanica the lowest level of expression for mj-far1 transcripts was detected within eggs and the highest in J2 within the first hours after root infection, which suggest a potential role of MJ-FAR during the different parasitic stages (Iberkleid et al. 2013). Using in situ hybridization, this work localized the Mhi-far-1 in the subventral oesophageal glands of $\mathrm{J} 2$ and the same localization, using different approaches, was identified for a protein similar to the Gp-FAR in the oesophageal glands of $M$. incognita, another FAR protein of the plant

Table 4 Pairwise sequence similarities between Meloidogyne hispanica (Mhi-vap-1, KF030969), M. arenaria (Ma-vap-1, KF030971), M. hapla (Mha-vap-1, MhA1_contig2874), M. incognita (Mi-vap-1, KF030970) and M. javanica (Mj-vap-1, KF030972) sequences of vap-1 gene using MEGA5 ${ }^{*}$

\begin{tabular}{lllll}
\hline & Mhi-vap-1 & Mi-vap-1 & Ma-vap-1 & Mj-vap-1 \\
\hline Mi-vap-1 & 97.5 & & & \\
Ma-vap-1 & 100 & 97.5 & & \\
Mj-vap-1 & 100 & 97.5 & 100 & \\
Mha-vap-1 & 83.7 & 81.4 & 83.7 & 83.7 \\
\hline
\end{tabular}

*Analyses were conducted using the Maximum Likelihood model included for comparison. The percentage of replicate trees in which the associated taxa clustered together in the bootstrap test (500 replicates) is shown next to the branches

parasitic nematode $D$. africanus was also identified in the oesophageal glands (Bellafiore et al. 2008; Haegeman et al. 2009).

However, in contrast with this work, G. pallida and $M$. javanica FAR-1 proteins have been shown to be highly expressed in the migratory and parasitic $\mathrm{J} 2$ with transcription in the nematode surface and also within the adult female body, using immunolocalization studies with the same antiserum (Prior et al. 2001; Iberkleid et al. 2013). Although M. hispanica far-1 formed a well supported clade (100\%) with $M$. incognita it showed only $67 \%$ bootstrap with $M$. javanica which could

Table 5 Pairwise sequence similarities between Meloidogyne hispanica (Mhi-far-1, KF030974), M. arenaria (Ma-far-1, KF030973), M. hapla (Mha-far-1, Mh10g200708_contig113) M. incognita (Mi-far-1, KF030975), M. javanica (Mj-far-1, KF030976) and Globodera pallida (Gp-far-1, CAA70477.2) sequences of $f a r-1$ gene using MEGA $5^{*}$

Mhi-far-1 Mi-far-1 Mj-far-1 Ma-far-1 Mha-far-1

\begin{tabular}{llllll}
\hline Mi-far-1 & 100 & & & & \\
Mj-far-1 & 95.8 & 95.8 & & & \\
Ma-far-1 & 96.9 & 96.9 & 94.8 & & \\
Mha-far-1 & 87.7 & 87.7 & 87.1 & 88.3 & \\
Gp-far-1 & 55.5 & 55.5 & 53.6 & 55.9 & 53.6 \\
\hline
\end{tabular}

*Analyses were conducted using the Maximum Likelihood model 
account for a particular mode of parasitism adaptation of this gene in $M$. hispanica and M. incognita.

We also showed in this paper that the localization of Mhi-far-1 is similar to M. incognita FAR protein but differs in $M$. hispanica in comparison with $M$. javanica (Bellafiore et al. 2008; Iberkleid et al. 2013).

The FAR-1 protein binds to linolenic and linoleic acid, which are precursors of plant defence compounds in the jasmonic acid signaling pathway (Prior et al. 2001; Curtis 2007). It was recently detected in the $M$. javanica cuticle surface and along the adjacent host root tissues and a continuous secretion of this protein into the intercellular space between the nematode body and the host cells was proposed (Iberkleid et al. 2013). The authors also reported that tomato plants over expressing of $M j$-far- 1 are highly susceptible to nematode infection indicating that the FAR protein might be involved in the manipulation of host lipid-based defences playing an important role in the parasitism of RKN (Iberkleid et al. 2013).

The localization of the expression of the genes vap-1 and far -1 in the subventral oesophageal glands suggest a potential parasitic function for these genes in $M$. hispanica. Further work is being conducted in order to assess whether the silencing of these genes affects $M$. hispanica behavior and whether they are essential for successful infection.

Acknowledgments This research was partially supported by FEDER funds through the "Programa Operacional Factores de Competitividade-COMPETE" and by national funds through FCT-Fundação para a Ciência e a Tecnologia under the project FCOMP-01-0124-FEDER-008722 (Ref ${ }^{\mathrm{a}}$. PTDC/AGR-AAM/ 103873/2008).

I. Tiago acknowledges a fellowship from FCT reference SFRH/BPD/75296/2010, funded by POPH-QREN-Tipology 4.1Advance Formation; European Social Fund; and MEC National Funds. PEst-C/SAU/LA0001/2013-2014 financed by FEDER COMPETE and by FCT.

\section{References}

Abrantes, I. M. de O., Vieira dos Santos, M. C., Conceição, I. L. P. M. da, Santos, M. S. N. de A., \& Volvas, N. (2008). Rootknot and other plant parasitic nematodes associated with fig trees in Portugal. Nematologia Mediterranea, 36, 131-136.

Bath, J. L., Robinson, M., Kennedy, M. W., Agbasi, C., Linz, L., Maetzold, E., et al. (2009). Identification of a secreted fatty acid and retinol-binding protein (Hp-FAR-1) from Heligmosomoides polygyrus. Journal of Nematology, 41, 228-233.
Bellafiore, S., \& Briggs, S. P. (2010). Nematode effectors and plant responses to infection. Current Opinion in Plant Biology, 13, 442-448.

Bellafiore, S., Shen, Z., Rosso, M. N., Abad, P., Shih, P., \& Briggs, S. P. (2008). Direct identification of the Meloidogyne incognita secretome reveals proteins with host cell reprogramming potential. PLoS Pathogens, 4, 1-12. e.00192.

Bin, A., Hawdon, J., Qiang, S., Hainan, R., Huiqing, Q., Wei, H., et al. (1999). Ancylostoma secreted protein 1 (ASP-1) homologues in human hookworms. Molecular and Biochemical Parasitology, 98, 143-149.

Chen, J., Hu, X., He, S., Wang, L., Hu, D., Wang, X., et al. (2010). Expression and immune response analysis of Schistosoma japonicum VAL-1, a homologue of vespid venom allergens. Parasitology Research, 106, 1413-1418.

Chitwoodi, D. J., \& Perry, R. N. (2009). Reproduction, physiology and biochemistry. In R. N. Perry, M. Moens, \& J. L. Starr (Eds.), Root-knot nematodes (pp. 182-200). Wallingford: CABI Publishing.

Curtis, R. H. (2007). Plant parasitic nematode proteins and the host-parasite interaction. Briefings in Functional Genomics and Proteomics, 6, 50-58.

Davis, K. G., \& Curtis, R. H. C. (2011). Cuticle surface coat of plant-parasitic nematodes. Annual Review of Phytopathology, 49, 135-156.

Davis, E. L., Hussey, R. S., Mitchum, M. G., \& Baum, T. J. (2008). Parasitism proteins in nematode-plant interactions. Current Opinion in Plant Biology, 11, 360-366.

De Boer, J. M., Yan, Y., Smant, G., Davis, E. L., \& Baum, T. J. (1998). In situ hybridization to messenger RNA in Heterodera glycines. Journal of Nematology, 30, 309312.

Ding, X., Shields, J., Allen, R., \& Hussey, R. S. (2000). Molecular cloning and characterization of a venom allergen AG5-like cDNA from Meloidogyne incognita. International Journal for Parasitology, 30, 77-81.

Felsenstein, J. (1985). Confidence limits on phylogenies: An approach using the bootstrap. Evolution, 39, 783-791.

Gao, B., Allen, R., Maier, T., Davis, E. L., Baum, T. J., \& Hussey, R. S. (2001). Molecular characterisation and expression of two venom allergen-like protein genes in Heterodera glycines. International Journal for Parasitology, 31, 16171625 .

Gao, B., Allen, R., Maier, T., Davis, E. L., Baum, T. J., \& Hussey, R. S. (2003). The parasitome of the phytonematode Heterodera glycines. Molecular Plant-Microbe Interactions, 16, 720-726.

Garofalo, A., Kläger, S. L., Rowlinson, M. C., Nirmalan, N., Klion, A., Allen, J. E., et al. (2002). The FAR proteins of filarial nematodes: secretion, glycosylation and lipid binding characteristics. Molecular and Biochemical Parasitology, 122, 161-170.

Haegeman, A., Jacob, J., Vanholme, B., Kyndt, T., Mitreva, M., \& Gheysen, G. (2009). Expressed sequence tags of the peanut pod nematode Ditylenchus africanus: the first transcriptome analysis of an Anguinid nematode. Molecular and Biochemical Parasitology, 167, 32-40.

Haegeman, A., Joseph, S., \& Gheysen, G. (2011). Analysis of the transcriptome of the root lesion nematode Pratylenchus coffeae generated by 454 sequencing technology. Molecular and Biochemical Parasitology, 178, 7-14. 
Haegeman, A., Mantelin, S., Jones, J. T., \& Gheysen, G. (2012). Functional roles of effectors of plant-parasitic nematodes. Gene, 492, 19-31.

Hawdon, J. M., Narasimhan, S., \& Hotez, P. J. (1999). Ancylostoma secreted protein 2: Cloning and characterization of a second member of a family of nematode secreted proteins from Ancylostoma caninum. Molecular and Biochemical Parasitology, 99, 149-66.

Hirschmann, H. (1996). Meloidogyne hispanica n. sp. (Nematoda: Meloidogynidae), the "Seville root-knot nematode". Journal of Nematology, 18, 520-532.

Huang, G., Gao, B., Maier, T., Allen, R., Davis, E. L., Baum, T. J., et al. (2003). A profile of putative parasitism genes expressed in the esophageal gland cells of the root-knot nematode Meloidogyne incognita. Molecular Plant-Microbe Interactions, 16, 376-381.

Hussey, R. S., \& Barker, K. R. (1973). A comparison of methods of collecting inocula of Meloidogyne spp., including a new technique. Plant Disease Report, 57, 1025-1028.

Hussey, R. S., Huang, G., \& Allen, R. (2011). Microaspiration of esophageal gland cells and cDNA library construction for identity parasitism genes of plant-parasitism nematodes. Methods Molecular Biology, 712, 89-107.

Iberkleid, I., Vieira, P., de A. Engler, J., Firester, K., Spiegel, Y., \& Horowitz, B. (2013). Fatty acid-and retinol-binding protein, MJ-FAR-1 induces tomato host susceptibility to root-knot nematodes. PloS One, 8, e64586.

Jacob, J., Mitreva, M., Vanholme, B., \& Gheysen, G. (2008). Exploring the transcriptome of the burrowing nematode Radopholus similis. Molecular Genetics and Genomics, 280, 1-17.

Jones, D. T., Taylor, W. R., \& Thornton, J. M. (1992). The rapid generation of mutation data matrices from protein sequences. Computer Applications in the Biosciences, 8, 275-282.

Jones, J. T., Kumar, A., Pylypenko, L. A., Thirugnanasambandam, A., Castelli, L., Chapman, S., et al. (2009). Identification and functional characterization of effectors in expressed sequence tags from various life cycle stages of the potato cyst nematode Globodera pallida. Molecular Plant Pathology, 10, $815-828$.

Jukes, T. H., \& Cantor, C. R. (1969). Evolution of protein molecules. In H. N. Munro (Ed.), Mammalian protein metabolism (pp. 21-132). New York: Academic.

Kang, M. J., Kim, Y. H., \& Hahn, B. S. (2010). Expressed sequence tag analysis generated from a normalized fulllength cDNA library of the root-knot nematode (Meloidogyne incognita). Genes \& Genomics, 32, 553-562.

Kang, J. S., Koh, Y. H., Moon, Y. S., \& Lee, S. H. (2012). Molecular properties of a venom allergen-like protein suggest a parasitic function in the pinewood nematode Bursaphelenchus xylophilus. International Journal for Parasitology, 42, 63-70.

Lee, M.-H., \& Schedl, T. RNA in situ hybridization of dissected gonads (XXX, 2006). In WormBook (Eds.), The C. elegans research community, WormBook, http://www.wormbook.org.

Lozano-Torres, J. L., Wilbers, R. H. P., Gawronski, P., Boshoven, J. C., Finkers-Tomczak, A., Cordewener, J. H. G., et al. (2012). Dual disease resistance mediated by the immune receptor $\mathrm{Cf}-2$ in tomato requires a common virulence target of a fungus and nematode. Proceedings of the National Academy of Sciences, 109, 10119-10124.
Maleita, C. M., Vieira dos Santos, M. C., Curtis, R. H. C., Powers, S. J., \& Abrantes, I. M. de O. (2011). Effect of the Mi gene on reproduction of Meloidogyne hispanica on tomato genotypes. Nematology, 13, 939-949.

Maleita, C., Curtis, R., Powers, S. J., \& Abrantes, I. M. de O. (2012a). Effects of inoculum levels of Meloidogyne hispanica and M. javanica on nematode reproduction and growth of tomato genotypes. Phytopathologia Mediterranea, $51,566-576$.

Maleita, C., Curtis, R., \& Abrantes, I. M. de O. (2012b). Thermal requirements for the embryonic development and life cycle of Meloidogyne hispanica. Plant Pathology, 61, 1002-1010.

Maleita, C., Curtis, R., Powers, S., \& Abrantes, I. (2012c). Host status of Meloidogyne hispanica. European Journal of Plant Pathology, 133, 449-460.

Murray, J., Gregory, W. F., Gomez-Escobar, N., Atmadja, A. K., \& Maizels, R. M. (2001). Expression and immune recognition of Brugia malayi VAL-1, a homologue of vespid venom allergens and Ancylostoma secreted proteins. Molecular and Biochemical Parasitology, 118, 89-96.

Opperman, C. H., Bird, D. M., Williamson, V. M., Rokhsar, D. S., Burke, M., Cohn, J., et al. (2008). Sequence and genetic map of Meloidogyne hapla: a compact nematode genome for plant parasitism. Proceedings of the National Academy of Sciences, 105, 14802-14807.

Orui, Y. (1999). Species identification of Meloidogyne spp. (Nematoda: Meloidogynidae) in Japan by random amplified polymorphic DNA (RAPD-PCR). Japanese Journal of Nematology, 29, 7-14.

Pais, C. S., Abrantes, I. M. de O., Fernandes, M. F. M., \& de A. Santos, M. S. N. (1986). Técnica de electroforese aplicada ao estudo das enzimas dos nemátodes-das-galhasradiculares, Meloidogyne spp. Ciência Biológica Ecology and Systematics (Portugal), 6, 19-34.

Peng, H., Gao, B., Kong, L., Yu, Q., Huang, W., He, X., et al. (2013). Exploring the host parasitism of the migratory plantparasitic nematode Ditylenchus destructor by expressed sequence tags analysis. PLoS One, 8, e69579.

Prior, A., Jones, J. T., Blok, V. C., Beauchamp, J., Mcdermott, L., Cooper, A., et al. (2001). A surface associated retinol and fatty acid binding protein (Gp-FAR-1) from the potato cyst nematode Globodera pallida lipid binding activities, structural analysis and expression pattern. The Biochemical Journal, 356, 387-394.

Rosso, M.-N., \& Grenier, E. (2011). Other nematodes effectors and evolutionary constrains. In J. Jones, G. Gheysen, \& C. Fenoll (Eds.), Genomics and molecular genetics of plantnematode interactions (pp. 287-307). New York: Springer.

Rosso, M.-N., Hussey, R. S., Davis, E. L., Smant, G., Baum, T. J., Abad, P., et al. (2012). Nematode effectors proteins: targets and functions in plant parasitism. In F. Martin \& S. Kamoun (Eds.), Effectors in plant-microbe interactions (pp. 327-354). Oxford: Wiley-Blackwell.

Roze, E., Hanse, B., Mitreva, M., Vanholme, B., Bakker, J., \& Smant, G. (2008). Mining the secretome of the root-knot nematode Meloidogyne chitwoodi for candidate parasitism genes. Molecular Plant Pathology, 9, 1-10.

Saitou, N., \& Nei, M. (1987). The neighbor-joining method: A new method for reconstructing phylogenetic trees. Molecular Biology and Evolution, 4, 406-425. 
Tamura, K., Peterson, D., Peterson, N., Stecher, G., Nei, M., \& Kumar, S. (2011). MEGA5: Molecular evolutionary genetics analysis using Maximum Likelihood, Evolutionary Distance, and Maximum Parsimony Methods. Molecular Biology and Evolution, 28, 2731-2739.

Vanholme, B., Mitreva, M., Criekinge, W. V., Logghe, M., Bird, D., McCarter, J. P., et al. (2006). Detection of putative secreted proteins in the plant-parasitic nematode Heterodera schachtii. Parasitology Research, 98, 414-424.

Wang, X., Allen, R., Ding, X., Goellner, M., Maier, T., De Boer, J. M., et al. (2001). Signal peptide-selection of cDNA cloned directly from the esophageal gland cells of the soybean cyst nematode Heterodera glycines. Molecular Plant-Microbe Interactions, 14, 536-544.

Wang, X., Li, H., Hu, Y., Fu, P., \& Xu, J. (2007). Molecular cloning and analysis of a new venom allergen-like protein gene from the root-knot nematode Meloidogyne incognita. Experimental Parasitology, 117, 133-140.

Zuckerkandl, E., \& Pauling, L. (1965). Evolutionary divergence and convergence in proteins. In V. Bryson \& H. J. Vogel (Eds.), Evolving genes and proteins (pp. 97-166). New York: Academic. 